\title{
Current topics
}

\section{Dietary fibre in under- and overnutrition in childhood}

\author{
DENIS BURKITT, DAVID MORLEY, AND ALEC WALKER \\ Unit of Geographical Pathology, St Thomas's Hospital, Tropical Child Health Unit, \\ Institute of Child Health, London, and South African Institute for Medical Research, Johannesburg
}

SUMmARY Children in developing countries pass stools that are very different from those passed by children in Europe. These stools reflect a diet of unrefined carbohydrate with low-energy density, and which due to the large volume results in an energy deficit in the child. This energy deficit is now considered to be the major cause of the almost universal undernutrition. Much of the improved health in European children during the last century has probably arisen through better nutrition due to more-refined carbohydrates and to more fat in the diet. Over the same period as children have become healthier, diseases of civilisation have appeared. One factor in such diseases is clearly that of diet, and these diseases may partly be caused by the high-energy density and the low-dietary fibre content. Changes in diet offer the greatest hope for a rapid improvement in health. In the developing world we need to find a means for making foods with a high-energy density more easily available to overcome the undernutrition in childhood. In industrialised countries older children need to become accustomed to a diet of lower-energy density than at present, containing more unrefined carbohydrate and less fat.

Experience has shown that doctors trained in Europe and America who go to work in developing countries soon begin to overlook and almost to ignore the general levels of undernutrition in the majority of children they see. Equally, doctors trained in developing countries who come to work in Europe or America soon accept that many of the diseases they see in adults rarely exist in their own countries, at least not in the rural areas where most of the people live. These two different experiences may be related and if the arguments put forward are accepted, paediatricians have a responsibility to see that both at individual and national levels there are changes in diet for children.

Medical programmes have played only a minor part in the improvement of health in Europe during the last two centuries. McKeown ${ }^{1}$ argued that better sanitation, water supply, and hygiene were less important than better nutrition. Those who read his book and have worked in developing countries will realise that his arguments might have been even stronger had he appreciated the greater severity of diarrhoea, measles, and other conditions in undernourished children.
Part of the change in Western diets came about through the introduction of steel mills in the nineteenth century, and the progressive reduction in fibre, particularly cereal fibre, in the diet. At the same time sugar, and to some extent dairy products, became more widely available and as a result children in Europe were able to eat food with a highenergy content. In Third World countries the majority of children still live on unrefined foods and have a low fat content in their diet. As a result they have a diet inadequate in energy in the first 3 years of life. In Europe the progressive decline in dietary fibre intake and the excessive use of foods containing sugars and fats are considered by many to be among the major factors responsible for adult diseases so common in Europe but so rarely seen in the developing countries. Children in developing countries who eat little sugar, fat, or oils need to consume large quantities and they frequently need more than $1 \mathrm{~kg}$ of carbohydrate staples daily if they are to receive adequate energy. Incorporated in the staples are large quantities of dietary fibre; this fibre makes the volume and consistency of stools very different from stools passed by children here. 


\section{Children's stools}

Surprisingly little has been written about the amount of children's stools or the frequency with which they are passed. In Europe and America it is generally assumed that children should pass one stool a day. Children in developing countries pass stools much more often. There are hospital records of 3 stools a day in children recovering from malnutrition. ${ }^{2}$ Figures collected during a household survey ${ }^{3}$ showed a fairly similar pattern (Table 1).

Little is known not only about the volume of stool passed but also about the time it takes food digesta to traverse the alimentary tract. Information from some of the more satisfactory studies is given in Table 2. This shows that children in developing countries living on a rural diet have much shorter intestinal transit times and pass larger volumes of stool. The difference may be presumed to result from the larger amount of fibre from cereals and other starchy staple foods in their diet.

\section{Times at which diseases appear}

The diseases listed below are common in the West and each one generally appears or increases in

Table 1 Distribution of African children (\%) under 5 by age and number of stools passed in the 24 hours before the survey*

\begin{tabular}{lcccc}
\hline $\begin{array}{l}\text { No of stools in } \\
24\end{array}$ hours & \multicolumn{4}{l}{ Age (months) } \\
\cline { 2 - 5 } & $0-6$ & $7-12$ & $13-18$ & $19-60$ \\
\hline 0 & 7 & 3 & 9 & 4 \\
1 & 19 & 23 & 22 & 17 \\
2 & 30 & 37 & 36 & 41 \\
3 and over & 44 & 37 & 33 & 38 \\
\hline
\end{tabular}

*This information was collected from 2 areas in west Africa and 2 from east Africa, by a random survey of homes. As each area gave a similar result, they were analysed together. The result was a modal value of 2 stools passed a day; however, more than one-third of the children passed 3 stools a day. frequency as a community adopts a Western way of life. The order in which these diseases appear is similar to the order in which they appear with increasing age in industrial countries. ${ }^{4}$ In industrial countries the prevalences of three diseases, with the exception of appendicitis, also increase with age. These observations suggest that this group of diseases is in part the result of various periods of exposure to the same environmental factors.

\section{Diseases related to the volume and consistency of stools}

Constipation. Fibre, and cereal fibre in particular, has the property of holding water in the large-bowel. It is becoming increasingly accepted that inadequate fibre in the diet is the fundamental cause of most constipation. ${ }^{5}$ Any visitor to rural areas in developing countries where sanitation facilities are nonexistent will soon notice that stools are very different in character from those evident in Western countries. Such stools are large and soft and often unformed, unlike the low-volume viscid stools often with scybala passed by people in the West.

\section{Some effects of constipation}

Appendicitis. This is rare in rural areas of developing countries, but it is one of the first of the characteristically Western diseases to emerge as Western foods are adopted. Appendicitis was one disease that became less common in wartime with rationing and an increase in dietary fibre. Appendicitis is believed to be initially due to obstruction of the appendix lumen most often caused by the presence in it of solid faecal particles. Such particles are rarely found in the appendix in communities with a low prevalence of appendicitis, and they are the result of excessive extraction of water from the faeces owing to a deficiency of fibre in the diet. ${ }^{6}$

Table 2 Transit time and weight of stools passed by children from different countries

\begin{tabular}{|c|c|c|c|c|}
\hline Origin of children & Age range (years) & $\begin{array}{l}\text { Mean time (and range) } \\
\text { of appearance } \\
\text { of marker (hours) }\end{array}$ & $\begin{array}{l}\text { Mean transit time } \\
\text { (and range) (hours) }\end{array}$ & $\begin{array}{l}\text { Mean weight (and } \\
\text { range) of stool/day }(\mathrm{g})\end{array}$ \\
\hline $\begin{array}{l}\text { African }(n=500) \text { (traditional diet) } \\
\text { (A R P Walker, unpublished data) }\end{array}$ & $13-18$ & $13(5-28)$ & $34(20-48)$ & $275(150-350)$ \\
\hline $\begin{array}{l}\text { African }(n=500) \text { (partly Westernised diet) } \\
\text { (A R P Walker, unpublished data) }\end{array}$ & $13-18$ & $29 \quad(9-40)$ & $45(24-59)$ & $165(120-260)$ \\
\hline $\begin{array}{l}\text { African }(n=30) \text { (partly Westernised diet) } \\
\text { (A R P Walker, unpublished data) }\end{array}$ & $10-12$ & $10 *(8-15)$ & - & $75(55-90)$ \\
\hline $\begin{array}{l}\text { Canadian }(\mathrm{n}=46) \\
\text { (B F Habbick et al., 1978, personal } \\
\text { communication) }\end{array}$ & $3-13$ & 33 (14-96) & $49(20-101)$ & $78(30-205)$ \\
\hline $\begin{array}{l}\text { English } 18(n=65) \\
\quad \text { (normal) }\end{array}$ & $3-12$ & $26^{*}(24-96)$ & - & 一 \\
\hline $\begin{array}{l}\text { English } 18(n=65) \\
\quad \text { (constipated) }\end{array}$ & $3-12$ & $80 *(48-168)$ & - & - \\
\hline
\end{tabular}

*Carmine marker, radio-opaque markers were used for the rest. 
Diverticular disease of the colon. As with constipation, most gastroenterologists agree that this common intestinal disorder is the direct result of a fibredeficient diet. It is the pressures generated to propel unnaturally viscid content through the bowel that force out the diverticula. ${ }^{7}$ Fibre-rich diets remove or alleviate symptoms in most patients and have reduced the number of patients requiring surgery by up to $90 \%$.

Large-bowel cancer. This is the second most common cause of death from cancer in the West but it is fairly rare in developing countries. As the faeces become more concentrated and are in longer contact with the bowel mucosa any carcinogens are more likely to have an effect due to these purely physical changes. $^{8}$

Varicose veins and haemorrhoids. The passage of these much harder and smaller stools necessitates the assistance of abdominal straining, thus increasing intra-abdominal pressures. These regular increases in intra-abdominal pressures applied to the major veins in the abdomen force blood retrogradely into the veins of the anal canal and the lower limbs. Such straining has been implicated as one of the factors in the production of varicose veins and, together with the strain of evacuating hard stools, has been implicated in the causation of haemorrhoids. ${ }^{49}$

Hiatus hernia. Raised abdominal pressures also force upwards the gastro-oesophageal junction into the thoracic cavity producing an anatomical change that constitutes a hiatus hernia. ${ }^{10}$

\section{Diseases not directly related to volume of stool and transit time}

Diabetes. This is a rare disease in rural areas of developing countries. However, it is now common in India and in the cities of Africa, and is one of the first diseases to appear with the change of life associated with industrialisation. Diabetes is rare among traditionally-living people, it is very common in affluent societies, it increases in prevalence after the adoption of a Western diet, and it has been shown to regress with a return to a diet more comparable to that of Third World communitiesthat is with a high content of minimally processed carbohydrate and a low intake of fat. ${ }^{11-12}$

Certain constituents of fibre, and guar gums in particular, increase the viscosity of intestinal content, thereby reducing the rate of absorption of nutrients from the gut. This reduces the insulin demands made by fibre-depleted carbohydrate foods. ${ }^{13}$ Moreover clinical trials have unequivocably demonstrated the value of diets composed largely of fibre-rich, starchy carbohydrate foods. ${ }^{12}$

Gallstones. These are now believed to arise if there is an excess of cholesterol relative to the solvent bile acid chenodeoxycholate, ${ }^{14}$ and therapeutically they can be treated by administration of chenodeoxycholate derived from animal sources. The consumption of millers' bran has also been shown to increase the production of chenodeoxycholate. ${ }^{15}$ Eating foods with a high-energy concentration is likely to be one factor in the production of obesity, and excessive energy intake predisposes to gallstone formation.

Ischaemic heart disease. The atherosclerotic changes in arterial walls which are so rarely found in those living in developing countries start early in life in industrial societies. In experimental studies on small animals atherosclerosis is less severe during the consumption of diets high in crude fibre. In one of Morris's studies on ischaemic heart disease a retrospective investigation of records showed a significant diminution in the condition among those who were eating more fibre of cereal origin rather than that of fruit and vegetables. ${ }^{16}$ Although smoking and excessive fat consumption have received the most attention as contributors to the causation of ischaemic heart disease, evidence is accumulating that fibre-rich carbohydrate foods may confer some protection. ${ }^{16}$

Obesity. Since fibre provides bulk without energy in food it is believed to mitigate against excessive energy intake. Fibre-rich foods satisfy hunger more readily than do foods of equal calorie value deprived of their fibre. ${ }^{17}$

\section{Discussion}

During the last two centuries there has been a change in Europe and whereas most deaths used to occur early in childhood, deaths nowadays are more often due to diseases we now relate to industrialisation. In rural areas of developing countries more than three-quarters of the children generally lack adequate growth. This growth failure is due to an inadequate energy intake rather than to a protein deficiency. In the cities of these countries growth among the élite children is frequently similar to that of children in the West although it may take two or more generations to catch up completely. At the same time in these cities diseases of industrialisation are becoming more common and unfortunately are causing premature deaths in those adults in 


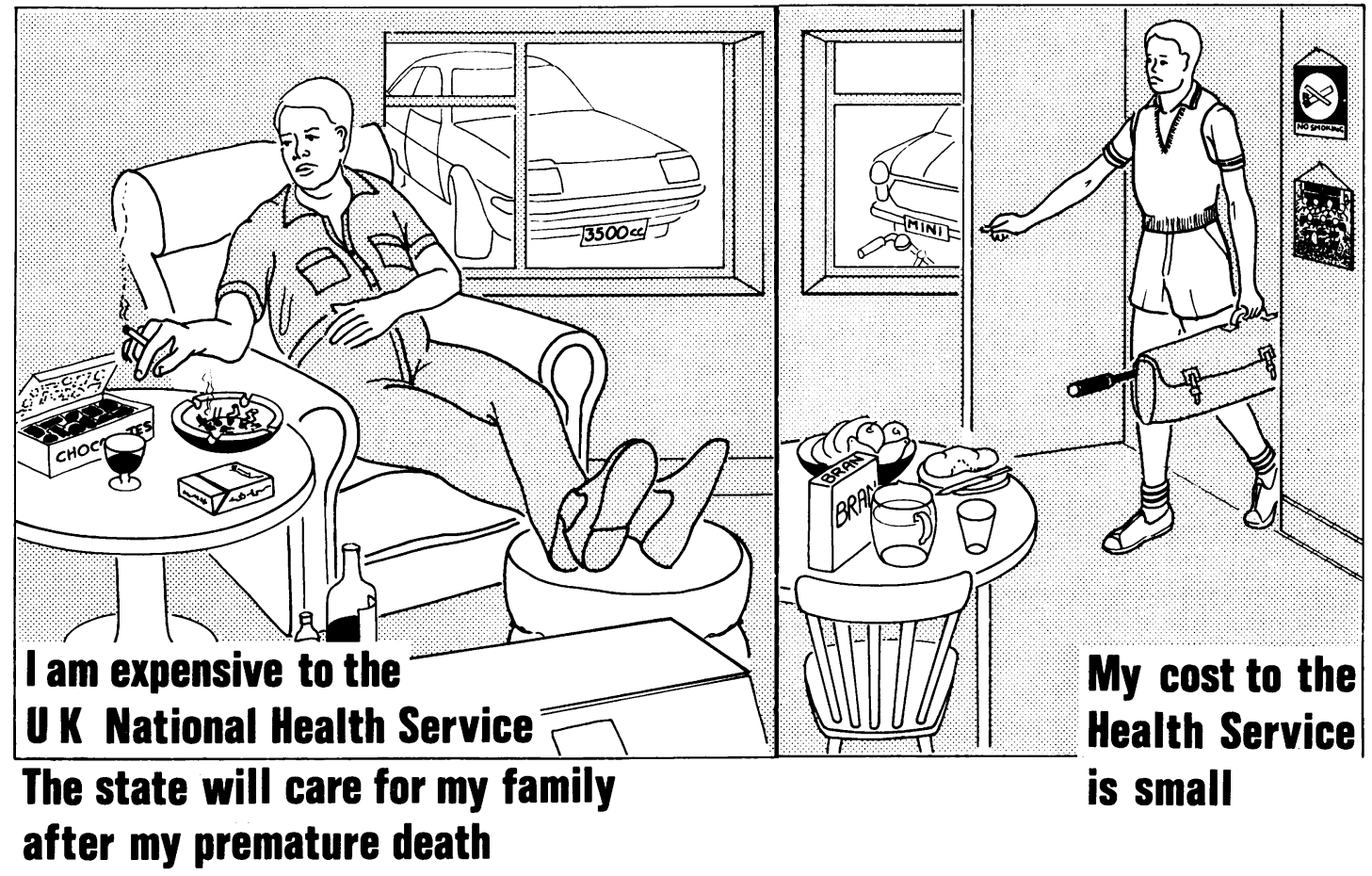

Figure Two lifestyles, either of which may be learnt in childhood. Diet probably has the greatest influence.

whom the country had placed a high investment in education and training. There are clearly many factors in this change and the decrease in dietary fibre is but one. These changes in life style are summarised in the Figure. The arguments relating diet to disease are of particular importance to the paediatrician in that changes of diet, if they are to be effective, need to be initiated early in life not only because these are long-term effects but also because dietary change in a population is more easily brought about in childhood. During 5 years in a rural hospital in west Africa chronic constipation was not seen once. Most paediatricians and general practitioners would now consider that increase in dietary fibre, and particularly of cereal fibre, plays an important part in the prevention and therapeutic management of this condition. The paediatrician should consider whether this advice should not be given to every mother as one step in the prevention of so many diseases characteristic of our affluent societies. Similarly, at national level, if the paediatrician is to play some part in reducing the resources spent on these presumably preventable conditions, steps to increase dietary fibre intake through increased consumption of brown or preferably wholemeal bread, together with fibre-rich breakfast cereals, are a priority.
References

1 McKeown T. The modern rise of population. London: Arnold, 1977.

2 Spalding E, McCrea J, Rutishauser I H E, Parkin J M. A study of severely malnourished children in the Gambia. J Trop Pediatr 1977; 23: 215-9.

${ }^{3}$ Senanayake P. Evaluation of a health care system for children under five years of age in Africa. PhD thesis, University of London, 1975.

4 Burkitt D P. Varicose veins; facts and fantasy. Arch Surg 1976; 111: 1327-32.

5 Avery Jones F, Godding E W. Management of constipation. Oxford: Blackwell, 1977: 97.

6 Burkitt D P. Appendicitis. In : Burkitt D P, Trowell H C, eds. Refined carbohydrate foods and disease. London: Academic Press, 1975: 87.

7 Painter N S. Diverticular disease of the colon. London: Heinemann Medical, 1975.

8 Walker A R P, Burkitt D P. Colonic cancer: hypotheses of causation, dietary prophylaxis, and future research. Am J Dig Dis 1976; 21: 910-7.

9 Burkitt D P, Graham-Stewart C W. Haemorrhoids: postulated pathogenesis and proposed prevention. Postgrad Med J 1975; 51: 631-6.

10 Burkitt D P. Hiatus hernia. In: Burkitt D P, Trowell H C, eds. Refined carbohydrate foods and disease. London: Academic Press, 1975: 161.

11 Trowell H C. Dietary fiber hypothesis of the etiology of diabetes mellitus. Diabetes 1975; 24: 762-5.

12 Anderson J W. Metabolic abnormalities contributing to diabetic complications. II. Peripheral nerves. $A m J$ Clin Nutr 1976; 29: 895-9. 
13 Jenkins D J A, Wolever T M S, Leeds A R, et al. Dietary fibres, fibre analogues, and glucose tolerance: importance of viscosity. Br Med J 1978; i: 1392-4.

14 Heaton K W. Are gallstones preventable? World Med 1978; 13: 21-3.

15 Pomare E W, Heaton $\mathrm{K}$ W. Alteration of bile salt metabolism by dietary fibre (bran). $B r M e d J ~ 1973$; iv: 262-4.

16 Morris J N, Marr J W, Clayton D G. Diet and heart; a postscript. Br Med J 1977; ii: 1307-14.

17 Haber G B, Heaton K W, Murphy D, Burroughs L F. Depletion and disruption of dietary fibre; effects on satiety, plasma-glucose, and serum insulin. Lancet 1977; ii: 679-82.

18 Dimpson S B. Carmine as an index of transit time in children with simple constipation. Arch Dis Child 1970; 45: 232-5.

Correspondence to Professor David Morley, Department of Tropical Child Health, Institute of Child Health, 30 Guilford Street, London WC1N 1EH.

Received 28 August 1979

The following articles will appear in future issues of this journal:

Thoughts on obesity. D Hull

Selection of patients with intractable epilepsy for resective surgery. C E Polkey

An objective undergraduate clinical examination in child health. $T$ Waterston, $I$ I Cater, and $R$ G Mitchell

Summer diarrhoea in African infants and children. $R M$ Robins-Browne, $C S$ Still, $M D$ Miliotis, $N J$ Richardson, HJ Koornhof, I Freiman, B D Schoub, G Lecatsas, and E Hartman

Presenting features of thoracic neuroblastoma. G R McLatchie and D G Young

Visual deterioration as presentation of subacute sclerosing panencephalitis. $H M$ Johnston, $G A$ Wise, and J G Henry 